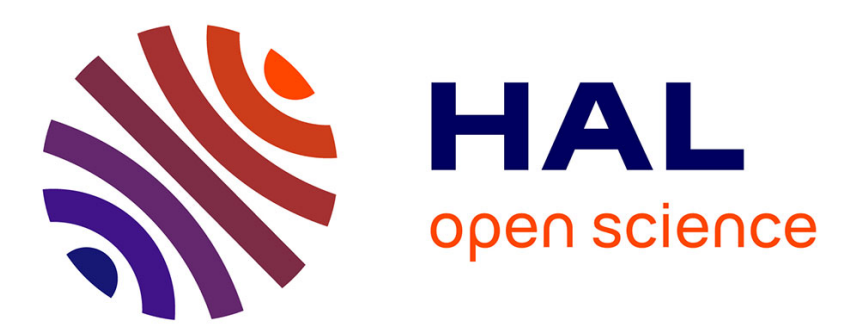

\title{
Phenanthrene degradation using Fe(III)-EDDS photoactivation under simulated solar light: A model for soil washing effluent treatment
}

\author{
Yufang Tao, Marcello Brigante, Hui Zhang, Gilles Mailhot
}

\section{- To cite this version:}

Yufang Tao, Marcello Brigante, Hui Zhang, Gilles Mailhot. Phenanthrene degradation using Fe(III)EDDS photoactivation under simulated solar light: A model for soil washing effluent treatment. Chemosphere, 2019, 236, pp.124366. 10.1016/j.chemosphere.2019.124366 . hal-02470626

\section{HAL Id: hal-02470626 \\ https://hal.science/hal-02470626}

Submitted on 7 Dec 2020

HAL is a multi-disciplinary open access archive for the deposit and dissemination of scientific research documents, whether they are published or not. The documents may come from teaching and research institutions in France or abroad, or from public or private research centers.
L'archive ouverte pluridisciplinaire HAL, est destinée au dépôt et à la diffusion de documents scientifiques de niveau recherche, publiés ou non, émanant des établissements d'enseignement et de recherche français ou étrangers, des laboratoires publics ou privés. 


\section{Phenanthrene degradation using Fe(III)-EDDS photoactivation under simulated solar light: A model for soil washing effluent treatment}

${ }^{a}$ Université Clermont Auvergne, CNRS, SIGMA Clermont, Institut de Chimie de Clermont-Ferrand, 63000 Clermont-Ferrand, France

${ }^{\mathrm{b}}$ Department of Environmental Engineering, School of Resources and Environmental Science, Wuhan University, 430079, P. R. China

*Corresponding author:

Pr. Gilles Mailhot :

Present/permanent address: Institut de Chimie de Clermont-Ferrand, Université Clermont Auvergne, 24 avenue Blaise Pascal, 63178 Aubière Cedex, France.

Tel : $0033(0) 661639920$

E-mail: gilles.mailhot@uca.fr 


\title{
Phenanthrene degradation using Fe(III)-EDDS photoactivation under simulated solar light: A model for soil washing effluent treatment
}

\author{
Yufang Tao $^{\mathrm{a}, \mathrm{b}}$, Marcello Brigante ${ }^{\mathrm{a}}$, Hui Zhang ${ }^{\mathrm{b} *}$, Gilles Mailhot ${ }^{\mathrm{a} *}$ \\ a Université Clermont Auvergne, CNRS, SIGMA Clermont, Institut de Chimie de \\ Clermont-Ferrand, 63000 Clermont-Ferrand, France \\ ${ }^{\mathrm{b}}$ Department of Environmental Engineering, School of Resources and Environmental Science, \\ Wuhan University, 430079, P. R. China
}

\section{Abstract}

In this work, for the first time, the nonionic surfactant polyoxyethylene-(20)-sorbitan monooleate (Tween $80, \mathrm{C}_{64} \mathrm{H}_{124} \mathrm{O}_{26}$ ) aided soil washing effluent was treated by enhanced activation of persulfate (PS) using Fe(III)-EDDS (EDDS: ethylenediamine-N, N-disuccinic acid) complexes under simulated solar light irradiation. The performance of this system was followed via the production and reactivity of radical species $\left(\mathrm{SO}_{4}{ }^{\bullet-}, \mathrm{HO}^{\bullet}, \mathrm{Cl}_{2}{ }^{\bullet-}\right)$ and degradation of phenanthrene (PHE) used as a model pollutant in soils. Different physico-chemical parameters such as the concentration of reactive species and $\mathrm{pH}$ were investigated through the PHE degradation efficiency. The second-order rate constants of the reactions for generated radicals with PHE and Tween 80 in solution were identified through competitive reaction experiments under steady-state conditions and application of nanosecond laser flash photolysis (LFP) as well. A kinetic approach was applied to assess the selectivity 
and reactivity of photo-generated radicals in aqueous medium in order to explain the observed degradation trends. This work proposes an innovative technology of management of soil washing solutions using $\mathrm{Fe}(\mathrm{III})$-EDDS complexes and solar light for the activation of persulfate.

Keywords: Advanced oxidation processes, sulfate radical, iron complexes, soil depollution, photochemistry.

\section{Introduction}

Soil contamination is known to be a severe and ubiquitous problem worldwide. Specially, soil pollution caused by hydrophobic organic compounds (HOCs) have attracted more attention and been taken seriously by governments and enterprises due to the characters of high-toxicity and long-refractory of this kind of pollutant. Polycyclic aromatic hydrocarbons (PAHs) are typical representatives of HOCs, which are notable and distinguished by their high health risks of mutability, carcinogenicity and teratogenicity through long-term bioaccumulation in the environment (Yap et al., 2011; Li et al., 2012; Trellu et al., 2016). The characteristics of low solubility in water and poor mobility in soil of PAHs impede the elimination of this type of compound from soils. Comprehensive researches of in-situ technologies such as bioremediation (Tiehm et al., 1997), phytoremediation (Huang et al., 2004) and electrokinetic remediation (Reddy et al., 2006) technologies are available in the literature (Gan et al., 2009a). In Ye's (Ye et al., 1995) study of biodegradation of PAHs by Sphingomonas paucimobilis, after $16 \mathrm{~h}$ of incubation of pyrene, benz[a]anthracene $(\mathrm{B}[\mathrm{a}] \mathrm{A})$, benzo[a]pyrene $(\mathrm{B}[\mathrm{a}] \mathrm{P})$, benzo[b]fluoranthene $(\mathrm{B}[\mathrm{b}] \mathrm{F})$ for each with $10 \mathrm{mg} / \mathrm{L}$, the degradation percentage was $1.3 \pm$ $0.4,1.8 \pm 0.1,9.6 \pm 1,5.0 \pm 0.6$, respectively. Lee's group (Lee et al., 2008) compared four native Korean plant species for phytoremediation of phenanthrene (PHE) and pyrene, the maximum removal efficiency of phenanthrene was $>99 \%$, for pyrene was $94 \%$ in planted soil 
after 80 days of experiments. Maturi's group (Maturi and Reddy, 2006) investigated modified cyclodextrin enhanced electrokinetic remediation of PHE and Nickel contaminated soil, the optimal 10\% removal efficiency of PHE was achieved with $1 \%$ cyclodextrin addition after around 166 days elapsed duration. However, all these in-situ techniques present at least one non-negligible disadvantages such as time-consuming treatment requirements, low remediation efficiency and high economic input. In this case, $e x$-situ techniques represented by surfactant aided soil washing processes appeal to more and more researchers. During the past several decades, ex-situ soil washing (SW) and in-situ soil flushing (SF) techniques, improved by application of surfactants as the extracting agents, have exhibited high performances for PAH elimination from soils (Gan et al., 2009b; Mousset et al., 2014a). Nonionic surfactant Polyoxyethylene (20) sorbitan monooleate (Tween 80), Dodecyl polyglycol ether(Brij 35), Polyoxyethylene (10) isooctylphenyl ether (Triton X-100), anionic surfactant sodium dodecyl sulfate (SDS) and sodium dodecyl benzene sulphonate (SDBS) are commonly used in the literature of surfactant enhanced soil remediation (Mao et al., 2015). Among these surfactants, the application of Tween 80 (TW80) was more extensive and prominent due to its lower toxicity and higher solubility capacity (Cheng et al., 2008). Except for the common application for PAHs, TW80 was supposed to be an excellent alternative for numerous hydrophobic contaminants such as PAHs anthracene, fluoranthene, pyrene and phenanthrene (Alcántara et al., 2008; Peng et al., 2011), Petroleum Hydrocarbons (Huguenot et al., 2015), p-cresol (Rosas et al., 2011), Decabromodiphenyl ether (Zhou et al., 2007), 4,4'-dichlorobiphenyl (Chu and Kwan, 2003), p-Nitrochlorobenzene (Guo et al., 2009) and pesticides like Diazinon (Hernández-Soriano et al., 2012), DDT (Zheng et al., 2012). The application of TW80 in the remediation of PAHs contaminated soil is especially ubiquitous owing to its better solubilization characteristic than other surfactants. It was reported that TW80 was efficient for solubilizing a plenty of PAHs such as Pyrene, PHE, Fluorene, 
Acenaphthene, Naphthalene and TW80 exhibited superior capacity than other nonionc surfactants such as Tween 20, Triton X-100, Triton X-305, Triton X-405 (Zhu and Zhou, 2008). In another work, TW80 was suggested as the highest solubilization capacity than Brij35, TX100 and SDS for PHE on the basis of molar solubilization ratios (MSR) (Zhao et al., 2005). Nevertheless, as a consequence of these soil washing/flushing processes, a complicated mixture of waste liquids containing great loads of extractants, PAHs and other accompanying organics is generated and should be further treated to reduce the potential environment concern of discharge the effluent into environment. Owing to the complexity of the mixed components of SW solutions, the management and disposal are a tremendous challenge for environmental engineering (Rosas et al., 2013; Trellu et al., 2016). Soil washing effluent could be treated with biological method, adsorption techniques as well as Advanced oxidation process (AOPs). However, biological treatments bear the drawbacks of long duration and low efficiency (Gharibzadeh et al., 2016), while adsorption technologies possess potential risks since contaminants could not be completely discomposed (Ahn et al., 2008; Zhou et al., 2013; Li et al., 2014). In this case, AOPs including electrochemical oxidation (Gómez et al., 2010; Mousset et al., 2014c, b; Trellu et al., 2017a), ozone oxidation (Liu, 2018), photocatalytic oxidation (Zhang et al., 2011; Bai et al., 2019) have been developed to the most popular and common applied technology for PAHs and various surfactant involved soil washing effluent treatments. As reviewed in Table S1, AOPs based on radical oxidation mechanism could effectively decompose PAHs into various products during the processes of soil washing effluent treatment with PAHs dosage from $1 \mathrm{mg} \mathrm{L}^{-1}$ to around $200 \mathrm{mg} \mathrm{L}^{-1}$ and optimal surfactants ranging from $1 \mathrm{~g} \mathrm{~L}^{-1}$ to $10 \mathrm{~g} \mathrm{~L}^{-1}$. Among multiple AOPs, Sulfate radicals based advanced oxidation processes (SR-AOPs) have been widely applied as effective and practicable techniques for remediation of contaminated waters and soils (Yen et al., 2011; Wacławek et al., 2017). Persulfate $\left(\mathrm{S}_{2} \mathrm{O}_{8}{ }^{2-}, \mathrm{PS}\right)$ is an ideal alternative oxidant $\left(\mathrm{E}_{0}=2.01 \mathrm{~V}\right)$, 
which can be activated to produce stronger sulfate radicals $\left(\mathrm{SO}_{4}{ }^{\circ-}\right)\left(\mathrm{E}_{0}=2.6 \mathrm{~V}\right)$ by various chemical or physical methods (Usman et al., 2012). In addition to its strong oxidation capacity, sulfate radical has revealed several advantages over other oxidants. $\mathrm{SO}_{4}{ }^{\bullet-}$ is more stable than hydroxyl radical $\left(\mathrm{HO}^{\bullet}\right)$ and exhibits a longer half-life time as well as a wider $\mathrm{pH}$ range for the application (Anipsitakis and Dionysiou, 2004).

Iron, one of the chemical activators of PS, is the most abundant transition metal present in the earth's crust and exists in a variety of forms in water such as soluble, colloidal and particulate forms. In natural water, insoluble iron-containing oxides account for a large proportion (Faust and Zepp, 1993), while dissolved iron is only found in a small percentage and most of them exists in the form of complex with organic ligands (Zhou et al., 2004). Polycarboxylates and (amino-)polycarboxylates like citrate, malonate, oxalate, EDTA, etc. can react with ferric ions $\left(\mathrm{Fe}^{3+}\right)$ to form stable and strong complexes and improve its solubility and stability in natural water (Chen et al., 2007). Moreover, such (amino-)polycarboxylate complexes are reported to have strong and fast photochemical reactivity under sunlight irradiation giving rise to oxidative species (Zhang et al., 2009). Those iron complexes such as Fe(III)-EDTA, $\mathrm{Fe}(\mathrm{III})-\mathrm{EDDS}, \mathrm{Fe}(\mathrm{III})$-oxalate or $\mathrm{Fe}(\mathrm{III})$-citrate have exhibited high efficiency as photo-catalysts and as persulfate and hydrogen peroxide activators for the elimination of a variety of contaminants (Manenti et al., 2015; Miralles-Cuevas et al., 2018; Soriano-Molina et al., 2019). Ethylenediamine-N,N-disuccinic acid (EDDS) is a structural isomer of EDTA, and $[S, S]-E D D S,[R, R]-E D D S$ and $[R, S / S, R]-E D D S$ are three stereo isomers of EDDS. Among those isomers, [S,S]-EDDS is recognized and employed as a environmentally safe and friendly substitution for EDTA for environmental restoration since it is easier biodegradable than EDTA (Nagaraju et al., 2007).

In this work, Fe(III)-EDDS complex was used to improve the PS photo-activation for the phenanthrene (PHE) degradation in soil washing solution. Main physico-chemical parameters 
such as concentration of chemical species and $\mathrm{pH}$ were investigated using simulated solar radiation to generate the sulfate radical from PS. This work provides a novel proposal of application of Fe(III)-EDDS for soil washing effluent treatments.

\section{Experimental Details}

\subsection{Chemicals}

Tween 80 (TW80), phenanthrene (PHE) and ferric perchlorate $\left(\mathrm{Fe}\left(\mathrm{ClO}_{4}\right)_{3} \cdot 9 \mathrm{H}_{2} \mathrm{O}\right)$ were obtained from Sigma-Aldrich. Ethylenediamine-N,N-disuccinic acid trisodium salt solution (35\% in water) was purchased from Fluka. All the other used reagents and chemicals were of analytical grade and all the solutions employed in this work were prepared with purified water from Millipore Ultra-Pure System (18.2 M $\Omega \mathrm{cm})$. The stock solutions of Fe(III)-EDDS were a mixture of appropriate amount of newly prepared aqueous solutions of ferric perchlorate and EDDS at a stoichiometry ratio of 1:1.

\subsection{Preparation of the synthetic SW solution}

TW80 is one of the suggested and most applied enhancing-solubility nonionic surfactants that increases the solubility of HOCs due to its notable features of lower soil sorption capacity and critical micellar concentration (CMC), low toxic property as well as higher solubilization ability and higher cost-effectiveness (Mulligan et al., 2001). It is known that above CMC, the surface tension of HOCs varies with a much smaller slope and the solubility of HOCs is strongly improved (Trellu et al., 2016). The CMC of TW80 is equal to $0.016 \mathrm{~g} \mathrm{~L}^{-1}$ (López-Vizcaíno et al., 2012) which is much lower compared to other surfactants. Due to the above advantages, TW80 was chosen as the aiding compound and its solubilization capacity of PHE was investigated.

\subsection{Irradiation experiments and degradation kinetic}

$50 \mathrm{~mL}$ of samples were irradiated in a jacked cylindrical Pyrex reactor connected to water 
cooling system and placed in a rectangular wood box to prevent the interference from the external light sources. Four tubular lamps (Sylvania, F15W/350BL), used as irradiation sources, were fixed on the top of the wood box. The irradiation energy was determined employing an optical fiber with a charge coupled device (CCD) spectrophotometer (Ocean Optics USD $2000+$ UV-vis) previously calibrated with a DH-2000-CAL reference lamp. The energy reaching the reactor determined between 300 and $400 \mathrm{~nm}\left(1390 \mu \mathrm{W} \mathrm{cm}{ }^{-2}\right)$ was very closed to the typical solar emission in the same wavelength range (Bianco et al., 2016).

In Figure 1 emission spectrum of light sources and UV-vis absorption spectra of chemical species (carried out with a Cary 300 UV-visible spectrophotometer) were presented. An overlap between the emission spectrum of the lamps and the absorption spectrum Fe(III)-EDDS complex was highlighted. PHE absorbed in the ultraviolet region with two maxima at $252 \mathrm{~nm}$ and $295 \mathrm{~nm}$. The main absorption region was located at $\lambda<250 \mathrm{~nm}$ for PS and $\lambda<300 \mathrm{~nm}$ for PHE in TW80 solution. Fe(III)-EDDS clearly exhibited a broad but gradual decrease absorption at the region of wavelengths up to approximately $400 \mathrm{~nm}$ and the overlapping absorption with the lamp emission spectrum from $300 \mathrm{~nm}$ and $400 \mathrm{~nm}$ as well. All experiments were carried out at $293 \pm 2 \mathrm{~K}$ and solutions were magnetically stirred with a magnetic bar to insure the homogenous mixture of the solution. At regular intervals, $0.5 \mathrm{~mL}$ of sample was withdrawn and analyzed by an UPLC-UV system (Alliance) equipped with a photodiode array detector. The eluent was a mixture of water and acetonitrile $(30 / 70, \mathrm{v} / \mathrm{v})$ with isocratic mode in a flow rate of $1 \mathrm{~mL} \mathrm{~min}^{-1}$. The column was a Nucleodur 100-5 $\mathrm{C} 18$ of $150 \mathrm{~mm} \times 4.6 \mathrm{~mm}$ with particle size $5 \mu \mathrm{m}$. The pseudo-first-order decay of PHE was determined using the following exponential equation: 


$$
\frac{[P H E]}{[P H E]_{O}}=\exp \left(-k^{\prime} t\right)
$$

Where $[\mathrm{PHE}]_{0}$ and $[\mathrm{PHE}]$ are the initial and residual concentrations of PHE at time $t, k^{\prime}$ is the pseudo-first-order apparent rate constant $\left(\mathrm{s}^{-1}\right)$. The initial conversion rate of PHE $\left(\mathrm{R}_{\mathrm{PHE}}\right)$ was calculated as $\mathrm{R}_{\mathrm{PHE}}\left(\mathrm{M} \mathrm{s}^{-1}\right)=\mathrm{k}^{\prime} \times[\mathrm{PHE}]_{0}$. The retention time and the analysis of PHE were not modified by the presence of TW80. The pHs of the solutions were adjusted with $0.1 \mathrm{M}$ of $\mathrm{HClO}_{4}$ or $\mathrm{NaOH}$ solutions and no significant $\mathrm{pH}$ variation was observed during irradiation.

\subsection{Laser flash photolysis}

The determination of the second order rate constants were carried out with the nanosecond laser flash photolysis (LFP) apparatus from Applied Photophysics (LKS60). A $266 \mathrm{~nm}$ excitation was used to generate radicals from solution and apparatus description as well as competition kinetic approaches have been reported elsewhere and a brief description is given in the supplementary materials section (Huang et al., 2018).

\section{Results and discussion}

\subsection{PHE degradation under various systems}

The solubility of PHE was tested using different concentration of TW80 in water. The results reported in Figure SM1 indicate that PHE solubility increased with the concentration of TW80 and a maximum of PHE solubility was reached around $16 \mathrm{mg} \mathrm{L}^{-1}$ (corresponding to a concentration of $90 \mu \mathrm{M})$. This maximum of solubility of PHE was obtained from $0.5 \mathrm{~g} \mathrm{~L}^{-1}$ of TW80. This concentration of TW80 was then used to prepare PHE solution for all experiments.

The PHE degradation under simulated solar light at $\mathrm{pH} 3.5$, using different mixture of $\mathrm{Fe}(\mathrm{III})-\mathrm{EDDS}, \mathrm{Fe}(\mathrm{III})$ and PS is reported in Figure 2. Control experiments showed that very 
low degradation of PHE (less than 5\%) occurred with the involvement of Fe(III)-EDDS complex and PS in the dark. Under irradiation, the direct photolysis (without PS and iron complexes) of PHE was negligible, less than $8 \%$ and addition of Fe(III)-EDDS (0.5 mM) not significantly changed the efficiency of PHE degradation after 150 min of irradiation. As a contrary, about $30 \%$ removal of PHE was being achieved in the presence of PS (5 mM) with UVA light due to the photogeneration of sulfate radicals that contributed to PHE degradation. Under UVA irradiation with addition of Fe(III) to PS solution, almost $35 \%$ of PHE removal was obtained under irradiation. So, although $\mathrm{Fe}(\mathrm{III})$ can be photo-reduced to $\mathrm{Fe}(\mathrm{II})$ (Brand et al., 1998) which is able to activate PS leading to the generation of sulfate radicals (Anipsitakis and Dionysiou, 2004; Liang et al., 2004), only 5\% of PHE degradation was promoted compared to PS/UV system. In the system with replacement of Fe(III) by Fe(III)-EDDS (0.5 $\mathrm{mM})$ to PS solution, the performance was much more pronounced and PHE removal was remarkably strengthened under irradiation, especially in the first 30 minutes. This difference can be explained by the lower photoreactivity of Fe(III) aquacomplexes in comparison with Fe(III)-EDDS at pH around 3.5 (Catastini et al., 2004; Huang, 2012) since Fe(II) formation from $\mathrm{Fe}(\mathrm{III})$ aquacomplexes is lower than from Fe(III)-EDDS at $\lambda>300 \mathrm{~nm}$. Therefore, in the presence of PS, sulfate radical formation is more important with Fe(III)-EDDS (reactions 1 and 2):

$\mathrm{Fe}(\mathrm{III})-\mathrm{EDDS}+\mathrm{h} v \rightarrow[\mathrm{Fe}(\mathrm{III})-\mathrm{L}]^{*} \rightarrow \mathrm{Fe}(\mathrm{II})+\mathrm{EDDS}^{\bullet}$

$\mathrm{Fe}(\mathrm{II})+\mathrm{S}_{2} \mathrm{O}_{8}{ }^{2-} \rightarrow \mathrm{Fe}(\mathrm{III})+\mathrm{SO}_{4}{ }^{2-}+\mathrm{SO}_{4}{ }^{\bullet-}$

$$
\mathrm{Fe}(\mathrm{OH})^{2+}+\mathrm{h} v \rightarrow \mathrm{Fe}(\mathrm{II})+\mathrm{HO}^{\bullet}
$$

Under sun-simulated irradiation in the presence of Fe(III)-EDDS, PHE kinetic exhibited two 
different decay steps (Figure 2). In the first 30 mins of irradiation, Fe(III)-EDDS was almost completely degraded at $\mathrm{pH} 3.5$ (Figure 3) to produce $\mathrm{Fe}(\mathrm{II})$ which represented the rate-limiting parameter for $\mathrm{SO}_{4}{ }^{\bullet-}$ formation. In the second step, after complete decomposition of $\mathrm{Fe}(\mathrm{III})$-EDDS, iron remained in the form of $\mathrm{Fe}(\mathrm{III})$ aquacomplexes, and under the influence of UVA light, hydroxyl radical and Fe(II) could be generated as well (reaction 3) (Mailhot et al., 2002; Krýsová et al., 2003). In the presence of PS, Fe(II) led to Fe(III) again (reaction 2) and we were in the presence of the (photo)chemical cycle involving $\mathrm{Fe}(\mathrm{III})$ and $\mathrm{Fe}(\mathrm{II})$. In this system, the degradation of PHE was mainly attributed to the formation of $\mathrm{SO}_{4}{ }^{\bullet-}$ and $\mathrm{HO}^{\bullet}$ through analogous reactions obtained with $\mathrm{Fe}(\mathrm{III})$ aquacomplexes in solution and the subsequent cycle of $\mathrm{Fe}(\mathrm{III}) / \mathrm{Fe}(\mathrm{II})$. In fact, the degradation kinetic after 30 minutes followed the same profile compared with those obtained where PS was mixed with Fe(III) aquacomplexes.

Same experiments conducted at pH 7.0 (Figure SM2) indicated that an enhancement of PHE degradation was still acquired with $\mathrm{Fe}(\mathrm{III})$-EDDS, suggesting that the iron complex is photoactive also at higher $\mathrm{pH}(\mathrm{Wu}$ et al., 2014). As a contrary, a strong inhibition of PHE degradation occurred with the dosing of Fe(III) aquacomplexes and PS. This effect could be ascribed to the precipitation of $\mathrm{Fe}(\mathrm{III})$ at $\mathrm{pH}>4.0$, resulting in absorption of light by iron particles and a potential screening effect for the photolysis of PS and also a very low photoreactivity of precipitated iron species.

What should be noted is on the contrary of many studies involving iron species, in our system $\mathrm{UV} / \mathrm{PS} / \mathrm{Fe}$ (III)-EDDS no significant effect of $\mathrm{pH}$ in the range 3.0 to 8.5 was obtained (Figure SM3). This observation was quite surprising, if we compare with former studies (Wu et al., 
2014; Wu et al., 2015) but could be due to the presence of TW80 which modified the reactivity of radical species (see following results).

\subsection{Effect of $\mathrm{Fe}$ (III)-EDDS and PS concentrations}

The effects of persulfate (PS) and Fe(III)-EDDS concentrations were investigated on the PHE degradation efficiency. PHE degradation involving different concentrations of Fe(III)-EDDS with $5 \mathrm{mM}$ PS are reported in Figure 3A. An enhancement of PHE degradation, after 30 min of irradiation, more than 3 times was achieved with the Fe(III)-EDDS concentration increased from 0 to $0.5 \mathrm{mM}$ (Figure 3B). However, the degradation efficiency of PHE decreased with the further increase of iron complex concentration. In fact, a scavenging effect of $\mathrm{Fe}(\mathrm{III})-\mathrm{EDDS}$ and $\mathrm{Fe}(\mathrm{II})$ toward $\mathrm{SO}_{4}{ }^{\bullet-}$ was expected at higher concentrations (Peng et al., 2017; Yu et al., 2018). Considering that a second order rate constant of $9.9 \times 10^{9} \mathrm{M}^{-1} \mathrm{~s}^{-1}$ has been determined for the reaction between sulfate radical and Fe(II) (E. et al., 1966), it was possible to argue that scavenging effect of ferrous ions, that were more stable in solution at pH 3.5, became significant at higher dosage of Fe(III)-EDDS. The maximum degradation of PHE (33\%) after 30 mins was reached using 0.5 mM Fe(III)-EDDS, while after 150 minutes the highest degradation efficiency (55\%) was obtained with $0.25 \mathrm{mM}$ of $\mathrm{Fe}(\mathrm{III})$-EDDS (Fig.3B). This shift of the maximum efficiency after $30 \mathrm{~min}$ was attributed to the higher load of $\mathrm{Fe}(\mathrm{II})$ and EDDS at higher concentration of $\mathrm{Fe}(\mathrm{III})$-EDDS and so stronger scavenging effect of sulfate radicals.

To further explore the degradation performance of PHE in the system PS/Fe(III)-EDDS, the effect of persulfate concentration was investigated. As shown in Figure 4, PHE degradation efficiency was strongly promoted by increasing PS loading from 0 to $30 \mathrm{mM}$ both for the photolysis of PS alone in solution and in the presence of Fe(III)-EDDS. The influence of $\mathrm{Fe}(\mathrm{III})-\mathrm{EDDS}$ was much pronounced at higher concentration of persulfate. In the presence of Fe(III)-EDDS and after 150 min of irradiation, the enhancement of PHE degradation with 2 
$\mathrm{mM}$ of PS was less than $2 \%$ while with $5 \mathrm{mM}$ of PS the enhancement was around $18 \%$ and more than $50 \%$ with 15 and $30 \mathrm{mM}$ of PS.

These results suggested that Fe(III)-EDDS had stronger impact at higher concentration of PS showing that the generation of sulfate radical through reaction between PS and Fe(II) was the main contribution of the efficiency of the system.

\subsection{Effect of $\mathrm{Fe}(\mathrm{III}) / \mathrm{EDDS}$ ratio}

According to previously reported works; the ratio of $\mathrm{Fe}(\mathrm{III})$ and EDDS concentrations represented a key parameter for the efficiency of the pollutants removal in water (Li et al., 2010). The concentration of PS was kept constant at $5 \mathrm{mM}$ while various initial loads of $\mathrm{Fe}(\mathrm{III})$ were applied. As shown in Figure SM4, the initial degradation rate of PHE increased with a higher concentration of $\mathrm{Fe}(\mathrm{III})$. At $1 \mathrm{mM}$ of $\mathrm{Fe}(\mathrm{III})$ the final elimination of PHE was higher than at 0.5 or $0.25 \mathrm{mM}$. This observation was resulted from the fact that at $1 \mathrm{mM}$ of $\mathrm{Fe}(\mathrm{III})$, there were in solution $0.5 \mathrm{mM}$ of $\mathrm{Fe}(\mathrm{III})$-EDDS and $0.5 \mathrm{mM}$ of $\mathrm{Fe}(\mathrm{III})$ aquacomplexes. The two iron species were photo-transformed into Fe(II) which could activate PS to generate sulfate radicals and moreover $\mathrm{Fe}(\mathrm{III})$ aquacomplexes generated photochemically also hydroxyl radicals. So in these conditions, a higher amount of sulfate and hydroxyl radicals were generated increasing the degradation of PHE. At concentrations of $\mathrm{Fe}(\mathrm{III})$ of 0.25 or 0.5 $\mathrm{mM}$, the final removals of PHE were very close with a little higher efficiency at $0.25 \mathrm{mM}$. During the first step of reactions, Fe(III) was reduced into Fe(II) and EDDS was oxidized. However if there were some residual EDDS remaining in solution, Fe(II) species were easily re-oxidized to Fe(III) and combined with EDDS to generate Fe(III)-EDDS complex (Li et al., 2010). As a consequence, the formation of $\mathrm{SO}_{4}{ }^{\bullet-}$ and the degradation of PHE photoinduced by Fe(III)-EDDS complex could continue.

\subsection{Effect of TW80 concentration.}

To better explore the role of TW80 in this system, experiments with $0.5,0.75$ and $1 \mathrm{~g} \mathrm{~L}^{-1}$ of 
TW80 were carried out. The increase of the surfactant concentration from 0.5 to $1.0 \mathrm{~g} \mathrm{~L}^{-1}$ inhibited significantly PHE degradation (Figure SM5A). In fact, when TW80 concentration increased to a factor of 1.5 and 2, the apparent rate constant of PHE degradation was reduced by a factor 1.8 and 3.3 (Figure SM5B). The negative effect acquired at higher TW80 concentrations could be ascribed to the competition between TW80 and PHE for the reactivity with photogenerated sulfate radicals. In fact, as reported in Table 1, a second order rate constant between $\mathrm{SO}_{4}{ }^{\bullet-}$ and TW80 $\left(k_{T W 80, S_{4}}^{{ }^{-}}\right)$of $4.6 \pm 0.2 \times 10^{9} \mathrm{M}^{-1} \mathrm{~s}^{-1}$ has been determined (see SM for more details). At $0.5 \mathrm{~g} \mathrm{~L}^{-1}$ of TW80 and considering the reactivity between $\mathrm{SO}_{4}{ }^{\bullet-}$ and Fe(III)-EDDS and PS (Neta et al., 1988; Bianco et al., 2017) reported in literature, we can argue that about $33 \%$ of photogenerated $\mathrm{SO}_{4}{ }^{\bullet-}$ reacted with TW80 while only $7 \%$ with PHE in solution. However, increasing the concentration of TW80 to $1 \mathrm{~g} \mathrm{~L}^{-1}$, the values were respectively 49 and $5 \%$. Moreover, in previously works it has been suggested that PHE was trapped into the micelle core of the surfactant, leading to a lower availability toward oxidizing radicals (Trellu et al., 2016; Trellu et al., 2017b). The significant sulfate radical selectivity between TW80 and PHE clearly demonstrated that the concentration of TW80 was the major parameter determining the efficiency of oxidative treatment adopted for PHE removal.

\subsection{Effect of chloride ions addition}

Inorganic species such as chloride ions are widely present in soil, resulting in the presence of such ions into the effluent of the procedure of soil washing. However, the existence of chloride ions $\left(\mathrm{Cl}^{-}\right)$in wastewater has been reported to affect the degradation efficiency of contaminants during the advanced oxidation processes and more particularly in PS oxidation treatments (Huang et al., 2018; Zhang et al., 2018). Different roles of chloride ions $\left(\mathrm{Cl}^{-}\right)$are 
reported in the literature on the efficiency of $\mathrm{SO}_{4}{ }^{\bullet-}$ and $\mathrm{HO}^{\bullet}$ based oxidations. Generally, it is reported that $\mathrm{Cl}^{-}$acts as a radical scavenger that substantially inhibits the efficiency of UV based activation of $\mathrm{H}_{2} \mathrm{O}_{2}$ and $\mathrm{S}_{2} \mathrm{O}_{8}{ }^{2-}$ (Tsuneda et al., 2002). However, some researchers find that reactive species produced from chloride ions, chlorine and dichlorine radicals $\left(\mathrm{Cl}^{\bullet} / \mathrm{Cl}_{2}{ }^{\bullet-}\right)$, show high selectivity when react with organic pollutants and increase the efficiency of removal (Yang et al., 2014). Moreover, in other investigations it is suggested that $\mathrm{Cl}^{-}$could react with $\mathrm{SO}_{4}{ }^{\bullet-}$ to generate $\mathrm{HO}^{\bullet}$ in circumneutral and alkaline $\mathrm{pH}$ (Kiwi et al., 2000). In addition, the involvement of $\mathrm{Cl}^{-}$is reported to modify the degradation mechanism using $\mathrm{SO}_{4}{ }^{\bullet-}$ based oxidation processes (Fang et al., 2012). As reported in Figure 5, complete degradation of PHE was achieved in 150 min of irradiation with $10 \mathrm{mM}$ of $\mathrm{Cl}^{-}$, while with 50 $\mathrm{mM}$ or $100 \mathrm{mM}$ of $\mathrm{Cl}^{-}$, the same efficiency could be obtained within $60 \mathrm{~min}$, demonstrating that the presence of higher dosages of $\mathrm{Cl}^{-}$remarkably enhanced PHE degradation using Fe(III)-EDDS under UVA irradiation. This result was totally distinguished with other studies where $\mathrm{Cl}^{-}$acted as an inhibitor or where its effect was negligible (Yang et al., 2016). To better understand the mechanism, for the first time, we determined the second order rate constants of $\mathrm{Cl}_{2}{ }^{\bullet-}$ with $\operatorname{PHE}\left(k_{P H E, C l} l_{2}^{-}\right)$and TW80 $\left(k_{T W 80, C l}^{\bullet_{2}^{-}}\right)$respectively at $4.6 \pm 0.3 \times 10^{8}$ $\mathrm{M}^{-1} \mathrm{~s}^{-1}$ and $7.1 \pm 0.1 \times 10^{6} \mathrm{M}^{-1} \mathrm{~s}^{-1}$ (table 1). This results suggested that second order rate constant between PHE and dichlorine radical anion $\left(k_{P H E, C l}{ }_{2}^{-}\right)$was almost 65 times higher than the one between TW80 and the same radical $\left(k_{T W 80, C l_{2}^{\bullet-}}\right)$. Therefore, $\mathrm{Cl}_{2}{ }^{\bullet-}$ generated by $\mathrm{Cl}^{-}$ exhibited much more selectivity to PHE in our soil washing solution. Moreover, the form of kinetics demonstrated that reactivity between $\mathrm{SO}_{4}{ }^{\bullet-}$ and $\mathrm{Cl}^{-}$played an important role to maintain PHE degradation, especially after 30 min of irradiation. 
345

If we simplified our chemical system considering that generated radical species $\left(\mathrm{HO}^{\bullet}, \mathrm{SO}_{4}{ }^{\circ-}\right.$, $\mathrm{Cl}_{2}{ }^{\circ}$ ) could react only with TW80 or PHE in solution, it was possible to explain, from a chemical kinetic point of view the impact of chloride on the system efficiency. In fact, in the absence of chloride ions mainly $\mathrm{SO}_{4}{ }^{--}$was generated in solution trough reaction (2) and photolysis of persulfate ions. Considering the concentration of chemical species (i.e. TW80 and PHE) and reactivity constant, about $82 \%$ of $\mathrm{SO}_{4}{ }^{\circ-}$ were trapped by TW80. However, if we considered that all $\mathrm{SO}_{4}{ }^{\circ-}$ was significantly converted into $\mathrm{Cl}_{2}{ }^{\circ-}$ (about $90 \%$ using $100 \mathrm{mM}$ of $\mathrm{Cl}^{-}$), in this case, the stronger reactivity between $\mathrm{Cl}_{2}{ }^{\circ-}$ and PHE compared to those determined for TW80 suggested that only $6 \%$ of $\mathrm{Cl}_{2}{ }^{\bullet-}$ react with the surfactant and 94\% with PHE.

\subsection{Radical species involvement}

In order to clearly clarify the significance of the different radicals formed during the process and their roles in this system and so further elucidate the oxidation mechanism of PHE degradation, free radicals scavenging tests were carried out. Methanol $(\mathrm{MeOH})$ was employed as scavenger for both $\mathrm{HO}^{\bullet}\left(k_{\mathrm{HO}}{ }^{\bullet}, \mathrm{MeOH}=9.7 \times 10^{8} \mathrm{M}^{-1} \mathrm{~S}^{-1}\right)$ and $\mathrm{SO}_{4}{ }^{--}\left(k_{\mathrm{SO}_{4}^{--}, \mathrm{MeOH}}=1.0 \times\right.$ $10^{7} M^{-1} S^{-1}$ ), and tert-Butanol (t-But) has higher selectivity for reactivity with $\mathrm{HO}^{\bullet}$ $\left(k_{H O^{\bullet}, t-B u t}=3.1 \times 10^{9} M^{-1} S^{-1}\right)$ than with $\mathrm{SO}_{4}^{\bullet-} \quad\left(k_{S O_{4}^{--}, t-B u t}=8.4 \times 10^{5} M^{-1} S^{-1}\right)$ (Buxton et al., 1988; Neta et al., 1988). With the addition of $50 \mathrm{mM}$ of tert-Butanol, PHE oxidation decreased (Figure.6), which revealed that $\mathrm{HO}^{\bullet}$ was partly responsible for PHE oxidation. PHE removal was more attenuated with methanol addition indicating that $\mathrm{SO}_{4}{ }^{\bullet-}$ was also radical species involved in the transformation of PHE. The degradation efficiency of PHE reduced from $48 \%$ (without scavenger) to $40 \%$ and $23 \%$ with tert-Butanol and methanol, respectively. 
With the different rate constants and concentrations of chemicals (TW80 and PHE) present in solution, we can deduce that, without scavengers about $18 \%$ of photogenerated $\mathrm{SO}_{4}{ }^{--}$and $13 \%$ of $\mathrm{HO}^{\bullet}$ reacted with PHE. However, i) In the presence of tert-Butanol $(50 \mathrm{mM}), \mathrm{HO}^{\bullet}$ radicals were almost completely trapped, only $0.3 \%$ of $\mathrm{HO}^{\bullet}$ still reacted on PHE. There was no effect on the percentage of $\mathrm{SO}_{4}{ }^{\bullet-}$ reacting with PHE. The addition of tert-Butanol resulted in $40 \%$ PHE degradation instead of $48 \%$. ii) With the addition of methanol $(50 \mathrm{mM})$, about $1 \%$ of $\mathrm{HO}^{\bullet}$ and $15 \%$ of $\mathrm{SO}_{4}{ }^{\bullet-}$ still reacted with PHE in solution. In this condition PHE concentration decreased by $25 \%$.

As a consequence, in the presence of tert-Butanol almost no more $\mathrm{HO}^{\bullet}$ reacted on $\mathrm{PHE}$ and the percentage of PHE degradation decreased by $8 \%$, while with the dosing of methanol only $1 \%$ of $\mathrm{HO}^{\bullet}$ and $15 \%$ of $\mathrm{SO}_{4}{ }^{\bullet-}$ reacted on PHE and the percentage of PHE degradation decreased by $25 \%$. With these data, we can evaluate that $1 \%$ of $\mathrm{SO}_{4}{ }^{\circ-}$ contributed to $6 \%$ of PHE degradation and $1 \%$ of $\mathrm{HO}^{\bullet}$ contributed only to $0.6 \%$ of PHE degradation. In another word $\mathrm{SO}_{4}{ }^{\bullet-}$ radicals contributed 10 times more than the $\mathrm{HO}^{\bullet}$ for the degradation of $\mathrm{PHE}$ in the presence of surfactant TW80. This result was not in agreement with the rate constant which was 1.4 times higher with $\mathrm{HO}^{\bullet}$ than with $\mathrm{SO}_{4}{ }^{\bullet-}$ (table 1). Thus, this result highlighted the surrounding environment of the pollutant for the efficiency of the radical species. PHE in surfactant presented an opposite reactivity with $\mathrm{HO}^{\bullet}$ and $\mathrm{SO}_{4}{ }^{\bullet-}$ if you compared with $\mathrm{PHE}$ alone in aqueous solution.

\section{Conclusion}

A novel application of $\mathrm{Fe}$ (III) complexes was studied to improve the photochemical activation of persulfate for treatments of soil washing effluent. Experimental parameters such as 
Fe(III)-EDDS concentration, PS concentration,TW80 concentration exhibited great effects on the PHE photodegradation in this system. The PHE degradation included two stages and the first period of $\mathrm{Fe}(\mathrm{III})$-EDDS decomposition was the rate-limiting step. Quenching experiments proved that $\mathrm{SO}_{4}{ }^{\bullet-}$ played a more important role than $\mathrm{HO}^{\bullet}$ on $\mathrm{PHE}$ degradation more particularly in the presence of surfactant which completely modified the reactivity of radical species. Moreover, we provided the evidence that the presence of chloride ions could significantly improve the PHE removal in this system. The higher selectivity of $\mathrm{Cl}_{2}{ }^{\bullet-}$ between PHE and TW80 was responsible for the efficiency increase.

\section{Acknowledgments}

We gratefully acknowledge the Ministry of Education of the PR of China for providing financial support for Yufang TAO to stay at the Institute of Chemistry of Clermont-Ferrand and Clermont Auvergne University in France. Authors acknowledge financial support from the Region Council of Auvergne, from the "Féderation des Recherches en Environnement" through the CPER "Environment" founded by the Region Auvergne, the French government, FEDER from the European Community from PRC program CNRS/NSFC n²70437 and from CAP 20-25 I-site project. 


\section{References}

Ahn, C., Kim, Y., Woo, S., Park, J., 2008. Soil washing using various nonionic surfactants and their recovery by selective adsorption with activated carbon. Journal of Hazardous Materials 154, 153-160.

Alcántara, M., Gómez, J., Pazos, M., Sanromán, M., 2008. Combined treatment of PAHs contaminated soils using the sequence extraction with surfactant-electrochemical degradation. Chemosphere 70, 1438-1444.

Anipsitakis, G.P., Dionysiou, D.D., 2004. Radical generation by the interaction of transition metals with common oxidants. Environ. Sci. Technol. 38, 3705-3712.

Bai, X., Wang, Y., Zheng, X., Zhu, K., Long, A., Wu, X., Zhang, H., 2019. Remediation of phenanthrene contaminated soil by coupling soil washing with Tween 80 , oxidation using the UV/S2O82- process and recycling of the surfactant. Chemical Engineering Journal.

Bianco, A., Passananti, M., Deguillaume, L., Mailhot, G., Brigante, M., 2016. Tryptophan and tryptophan-like substances in cloud water: Occurrence and photochemical fate. Atmos. Environ. 137, 53-61.

Bianco, A., Polo-López, M.I., Fernández-lbáñez, P., Brigante, M., Mailhot, G., 2017. Disinfection of water inoculated with Enterococcus faecalis using solar/Fe(III)EDDS- $\mathrm{H}_{2} \mathrm{O}_{2}$ or $\mathrm{S}_{2} \mathrm{O}_{8}{ }^{2-}$ process. Water Res. 118, 249-260.

Brand, N., Mailhot, G., Bolte, M., 1998. Degradation photoinduced by Fe(III): Method of alkylphenol ethoxylates removal in water. Environ. Sci. Technol. 32, 2715-2720.

Buxton, G.V., Greenstock, C.L., Helman, W.P., Ross, A.B., 1988. Critical review of rate constants for reactions of hydrated electrons, hydrogen atoms and hydroxyl radicals $\left({ }^{\circ} \mathrm{OH} /{ }^{\circ} \mathrm{O}^{-}\right.$) in aqueous solution. J. Phys. Chem. Ref. Data 17, 513-886.

Catastini, C., Rafqah, S., Mailhot, G., Sarakha, M., 2004. Degradation of amitrole by excitation of iron(III) aquacomplexes in aqueous solutions. J. Photochem. Photobiol., A 162, 97-103.

Chen, Y., Wu, F., Lin, Y., Deng, N., Bazhin, N., Glebov, E., 2007. Photodegradation of glyphosate in the ferrioxalate system. J. Hazard. Mater. 148, 360-365.

Cheng, K., Lai, K., Wong, J., 2008. Effects of pig manure compost and nonionic-surfactant Tween 80 on phenanthrene and pyrene removal from soil vegetated with Agropyron elongatum. Chemosphere 73, 791-797. Chu, W., Kwan, C.Y., 2003. Remediation of contaminated soil by a solvent/surfactant system. Chemosphere 53, 9-15.

E., H., A., H., G., B., 1966. Pulsradiolytische untersuchung des radikalanions $\mathrm{SO}_{4}{ }^{-}$. Ber. Bunsenges. Phys. Chem. 70, 149-154.

Fang, G.-D., Dionysiou, D.D., Wang, Y., Al-Abed, S.R., Zhou, D.-M., 2012. Sulfate radical-based degradation of polychlorinated biphenyls: Effects of chloride ion and reaction kinetics. J. Hazard. Mater. 227-228, 394-401.

Faust, B.C., Zepp, R.G., 1993. Photochemistry of aqueous iron(III)-polycarboxylate complexes: roles in the chemistry of atmospheric and surface waters. Environ. Sci. Technol. 27, 2517-2522.

Gan, S., Lau, E., Ng, H., 2009a. Remediation of soils contaminated with polycyclic aromatic hydrocarbons (PAHs). Journal of hazardous materials 172, 532-549.

Gan, S., Lau, E.V., Ng, H.K., 2009b. Remediation of soils contaminated with polycyclic aromatic hydrocarbons (PAHs). J. Hazard. Mater. 172, 532-549.

Gharibzadeh, F., Kalantary, R.R., Nasseri, S., Esrafili, A., Azari, A., 2016. Reuse of polycyclic aromatic hydrocarbons (PAHs) contaminated soil washing effluent by bioaugmentation/biostimulation process. Separation \& Purification Technology 168, 248-256.

Gómez, J., Alcántara, M., Pazos, M., Sanromán, M., 2010. Remediation of polluted soil by a two-stage treatment system: desorption of phenanthrene in soil and electrochemical treatment to recover the extraction agent. Journal of hazardous materials 173, 794-798. 
Guo, H., Liu, Z., Yang, S., Sun, C., 2009. The feasibility of enhanced soil washing of p-nitrochlorobenzene (pNCB) with SDBS/Tween80 mixed surfactants. Journal of Hazardous Materials 170, 1236-1241.

Hernández-Soriano, M.C., Mingorance, M.D., Peña, A., 2012. Desorption of two organophosphorous pesticides from soil with wastewater and surfactant solutions. Journal of Environmental Management 95, S223-S227.

Huang, W., 2012. Homogeneous and heterogeneous Fenton and photo-Fenton processes : impact of iron complexing agent ethylenediamine-N,N'-disuccinic acid (EDDS). Université Blaise Pascal - Clermont-Ferrand II. Huang, W., Bianco, A., Brigante, M., Mailhot, G., 2018. UVA-UVB activation of hydrogen peroxide and persulfate for Advanced Oxidation Processes: Efficiency, mechanism and effect of various water constituents. J. Hazard. Mater. 347, 279-287.

Huang, X.-D., El-Alawi, Y., Penrose, D.M., Glick, B.R., Greenberg, B.M., 2004. A multi-process phytoremediation system for removal of polycyclic aromatic hydrocarbons from contaminated soils. Environmental pollution 130 , 465-476.

Huguenot, D., Mousset, E., Van Hullebusch, E.D., Oturan, M.A., 2015. Combination of surfactant enhanced soil washing and electro-Fenton process for the treatment of soils contaminated by petroleum hydrocarbons. Journal of environmental management 153, 40-47.

Kiwi, J., Lopez, A., Nadtochenko, V., 2000. Mechanism and kinetics of the OH-radical intervention during Fenton oxidation in the presence of a significant amount of radical scavenger ( $\mathrm{Cl}^{-}$). Environ. Sci. Technol. 34, 2162-2168. Krýsová, H., Jirkovský, J.r., Krýsa, J., Mailhot, G., Bolte, M., 2003. Comparative kinetic study of atrazine photodegradation in aqueous $\mathrm{Fe}(\mathrm{ClO} 4) 3$ solutions and TiO2 suspensions. Applied Catalysis B: Environmental 40, $1-12$.

Lee, S.-H., Lee, W.-S., Lee, C.-H., Kim, J.-G., 2008. Degradation of phenanthrene and pyrene in rhizosphere of grasses and legumes. Journal of Hazardous Materials 153, 892-898.

Li, F., Guo, S., Hartog, N., 2012. Electrokinetics-enhanced biodegradation of heavy polycyclic aromatic hydrocarbons in soil around iron and steel industries. Electrochim. Acta 85, 228-234.

Li, H., Qu, R., Chao, L., Guo, W., Han, X., Fang, H., Ma, Y., Xing, B., 2014. Selective removal of polycyclic aromatic hydrocarbons (PAHs) from soil washing effluents using biochars produced at different pyrolytic temperatures. Bioresour Technol 163, 193-198.

Li, J., Mailhot, G., Wu, F., Deng, N., 2010. Photochemical efficiency of Fe(III)-EDDS complex: OH radical production and 17 $\beta$-estradiol degradation. J. Photochem. Photobiol., A 212, 1-7.

Liang, C., Bruell, C.J., Marley, M.C., Sperry, K.L., 2004. Persulfate oxidation for in situ remediation of TCE. II. Activated by chelated ferrous ion. Chemosphere 55, 1225-1233.

Liu, J., 2018. Soil remediation using soil washing followed by ozone oxidation. Journal of industrial and engineering chemistry $65,31-34$.

López-Vizcaíno, R., Sáez, C., Cañizares, P., Rodrigo, M.A., 2012. The use of a combined process of surfactant-aided soil washing and coagulation for PAH-contaminated soils treatment. Sep. Purif. Technol. 88, 46-51.

Mailhot, G., Sarakha, M., Lavedrine, B., Cáceres, J., Malato, S., 2002. Fe(III)-solar light induced degradation of diethyl phthalate (DEP) in aqueous solutions. Chemosphere 49, 525-532.

Manenti, D.R., Soares, P.A., Módenes, A.N., Espinoza-Quiñones, F.R., Boaventura, R.A.R., Bergamasco, R., Vilar, V.J.P., 2015. Insights into solar photo-Fenton process using iron(III)-organic ligand complexes applied to real textile wastewater treatment. Chem. Eng. J. 266, 203-212.

Mao, X., Jiang, R., Xiao, W., Yu, J., 2015. Use of surfactants for the remediation of contaminated soils: A review. Journal of Hazardous Materials 285, 419-435.

Maturi, K., Reddy, K.R., 2006. Simultaneous removal of organic compounds and heavy metals from soils by 
electrokinetic remediation with a modified cyclodextrin. Chemosphere 63, 1022-1031.

Miralles-Cuevas, S., Oller, I., Ruíz-Delgado, A., Cabrera-Reina, A., Cornejo-Ponce, L., Malato, S., 2018. EDDS as complexing agent for enhancing solar advanced oxidation processes in natural water: Effect of iron species and different oxidants. Journal of Hazardous Materials.

Mousset, E., Oturan, M.A., Van Hullebusch, E.D., Guibaud, G., Esposito, G., 2014a. Soil washing/flushing treatments of organic pollutants enhanced by cyclodextrins and integrated treatments: State of the art. Crit. Rev. Env. Sci. Tec. 44, 705-795.

Mousset, E., Oturan, N., Hullebusch, E.D.V., Guibaud, G., Esposito, G., Oturan, M.A., 2014b. Influence of solubilizing agents (cyclodextrin or surfactant) on phenanthrene degradation by electro-Fenton process - Study of soil washing recycling possibilities and environmental impact. Water Research 48, 306-316.

Mousset, E., Oturan, N., Hullebusch, E.D.V., Guibaud, G., Esposito, G., Oturan, M.A., 2014c. Treatment of synthetic soil washing solutions containing phenanthrene and cyclodextrin by electro-oxidation. Influence of anode materials on toxicity removal and biodegradability enhancement. Applied Catalysis B Environmental 160-161, 666-675.

Mulligan, C.N., Yong, R.N., Gibbs, B.F., 2001. Surfactant-enhanced remediation of contaminated soil: a review. Eng. Geol. 60, 371-380.

Nagaraju, V., Goje, T., Crouch, A.M., 2007. Determination of copper and iron using [S-S']-ethylenediaminedisuccinic acid as a chelating agent in wood pulp by capillary electrophoresis. Anal. Sci. 23, 493-496.

Neta, P., Huie, R.E., Ross, A.B., 1988. Rate constants for reactions of inorganic radicals in aqueous solution. J. Phys. Chem. Ref. Data 17, 1027-1284.

Peng, H., Zhang, W., Liu, L., Lin, K., 2017. Degradation performance and mechanism of decabromodiphenyl ether (BDE209) by ferrous-activated persulfate in spiked soil. Chem. Eng. J. 307, 750-755.

Peng, S., Wu, W., Chen, J., 2011. Removal of PAHs with surfactant-enhanced soil washing: influencing factors and removal effectiveness. Chemosphere 82, 1173-1177.

Reddy, K.R., Ala, P.R., Sharma, S., Kumar, S.N., 2006. Enhanced electrokinetic remediation of contaminated manufactured gas plant soil. Engineering Geology 85, 132-146.

Rosas, J., Vicente, F., Santos, A., Romero, A., 2011. Enhancing p-cresol extraction from soil. Chemosphere 84, 260-264.

Rosas, J.M., Vicente, F., Santos, A., Romero, A., 2013. Soil remediation using soil washing followed by Fenton oxidation. Chem. Eng. J. 220, 125-132.

Soriano-Molina, P., Plaza-Bolaños, P., Lorenzo, A., Agüera, A., García Sánchez, J.L., Malato, S., Sánchez Pérez, J.A., 2019. Assessment of solar raceway pond reactors for removal of contaminants of emerging concern by photo-Fenton at circumneutral $\mathrm{pH}$ from very different municipal wastewater effluents. Chemical Engineering Journal 366, 141-149.

Tiehm, A., Stieber, M., Werner, P., Frimmel, F.H., 1997. Surfactant-enhanced mobilization and biodegradation of polycyclic aromatic hydrocarbons in manufactured gas plant soil. Environmental Science \& Technology 31, 2570-2576.

Trellu, C., Mousset, E., Pechaud, Y., Huguenot, D., van Hullebusch, E.D., Esposito, G., Oturan, M.A., 2016. Removal of hydrophobic organic pollutants from soil washing/flushing solutions: A critical review. Journal of Hazardous Materials 306, 149-174.

Trellu, C., Oturan, N., Pechaud, Y., van Hullebusch, E.D., Esposito, G., Oturan, M.A., 2017a. Anodic oxidation of surfactants and organic compounds entrapped in micelles - Selective degradation mechanisms and soil washing solution reuse. Water Research 118, 1. 
Trellu, C., Oturan, N., Pechaud, Y., van Hullebusch, E.D., Esposito, G., Oturan, M.A., 2017b. Anodic oxidation of surfactants and organic compounds entrapped in micelles - Selective degradation mechanisms and soil washing solution reuse. Water Res. 118, 1-11.

Tsuneda, S., Ishihara, Y., Hamachi, M., Hirata, A., 2002. Inhibition effect of chlorine ion on hydroxyl radical generation in UV- $\mathrm{H}_{2} \mathrm{O}_{2}$ process. Water Sci. Technol. 46, 33-38.

Usman, M., Faure, P., Hanna, K., Abdelmoula, M., Ruby, C., 2012. Application of magnetite catalyzed chemical oxidation (Fenton-like and persulfate) for the remediation of oil hydrocarbon contamination. Fuel 96, 270-276.

Wacławek, S., Lutze, H.V., Grübel, K., Padil, V.V.T., Černík, M., Dionysiou, D.D., 2017. Chemistry of persulfates in water and wastewater treatment: A review. Chem. Eng. J. 330, 44-62.

Wu, Y., Bianco, A., Brigante, M., Dong, W., de Sainte-Claire, P., Hanna, K., Mailhot, G., 2015. Sulfate radical photogeneration using Fe-EDDS: influence of critical parameters and naturally occurring scavengers. Environmental science \& technology 49, 14343-14349.

Wu, Y., Brigante, M., Dong, W., de Sainte-Claire, P., Mailhot, G., 2014. Toward a better understanding of Fe(III)-EDDS photochemistry: Theoretical stability calculation and experimental investigation of 4-tert-butylphenol degradation. J. Phys. Chem. A 118, 396-403.

Yang, Y., Pignatello, J.J., Ma, J., Mitch, W.A., 2014. Comparison of halide impacts on the efficiency of contaminant degradation by sulfate and hydroxyl radical-based advanced oxidation processes (AOPs). Environ. Sci. Technol. 48, 2344-2351.

Yang, Y., Pignatello, J.J., Ma, J., Mitch, W.A., 2016. Effect of matrix components on UV/ $\mathrm{H}_{2} \mathrm{O}_{2}$ and $\mathrm{UV} / \mathrm{S}_{2} \mathrm{O}_{8}{ }^{2-}$ advanced oxidation processes for trace organic degradation in reverse osmosis brines from municipal wastewater reuse facilities. Water Res. 89, 192-200.

Yap, C.L., Gan, S., Ng, H.K., 2011. Fenton based remediation of polycyclic aromatic hydrocarbons-contaminated soils. Chemosphere 83, 1414-1430.

Ye, D., Siddiqi, M.A., Maccubbin, A.E., Kumar, S., Sikka, H.C., 1995. Degradation of polynuclear aromatic hydrocarbons by Sphingomonas paucimobilis. Environmental science \& technology 30, 136-142.

Yen, C.-H., Chen, K.-F., Kao, C.-M., Liang, S.-H., Chen, T.-Y., 2011. Application of persulfate to remediate petroleum hydrocarbon-contaminated soil: Feasibility and comparison with common oxidants. J. Hazard. Mater. 186, 2097-2102.

Yu, S., Gu, X., Lu, S., Xue, Y., Zhang, X., Xu, M., Qiu, Z., Sui, Q., 2018. Degradation of phenanthrene in aqueous solution by a persulfate/percarbonate system activated with CA chelated-Fe(II). Chem. Eng. J. 333, 122-131.

Zhang, C., Wang, L., Pan, G., Wu, F., Deng, N., Mailhot, G., Mestankova, H., Bolte, M., 2009. Degradation of atrazine photoinduced by Fe(III)-pyruvate complexes in the aqueous solution. J. Hazard. Mater. 169, 772-779.

Zhang, W., Zhou, S., Sun, J., Meng, X., Luo, J., Zhou, D., Crittenden, J., 2018. Impact of chloride ions on UV/ $\mathrm{H}_{2} \mathrm{O}_{2}$ and UV/persulfate advanced oxidation processes. Environ. Sci. Technol. 52, 7380-7389.

Zhang, Y., Wong, J., Liu, P., Yuan, M., 2011. Heterogeneous photocatalytic degradation of phenanthrene in surfactant solution containing TiO2 particles. Journal of hazardous materials 191, 136-143.

Zhao, B., Zhu, L., Li, W., Chen, B., 2005. Solubilization and biodegradation of phenanthrene in mixed anionic-nonionic surfactant solutions. Chemosphere 58, 33-40.

Zheng, G., Selvam, A., Wong, J.W.C., 2012. Enhanced Solubilization and Desorption of Organochlorine Pesticides (OCPs) from Soil by Oil-Swollen Micelles Formed with a Nonionic Surfactant. Environmental Science \& Technology 46, 12062-12068.

Zhou, D., Wu, F., Deng, N., 2004. Fe(III)-oxalate complexes induced photooxidation of diethylstilbestrol in water. Chemosphere 57, 283-291.

Zhou, J., Jiang, W., Ding, J., Zhang, X., Gao, S., 2007. Effect of Tween 80 and $\beta$-cyclodextrin on degradation of 
decabromodiphenyl ether (BDE-209) by white rot fungi. Chemosphere 70, 172-177.

583 Zhou, W., Wang, X., Chen, C., Zhu, L., 2013. Removal of polycyclic aromatic hydrocarbons from surfactant 584 solutions by selective sorption with organo-bentonite. Chemical Engineering Journal 233, 251-257.

585 Zhu, L., Zhou, W., 2008. Partitioning of polycyclic aromatic hydrocarbons to solid-sorbed nonionic surfactants. 586 Environmental pollution 152, 130-137. 
589 Table 1: Second-order rate constants $\left(\mathrm{M}^{-1} \mathrm{~s}^{-1}\right)$ of TW80 and PHE with different radicals 590 determined using LFP and competition kinetic method.

\begin{tabular}{cccc}
\hline Compounds & $k_{\mathrm{HO}}$ & $k_{\mathrm{SO}_{4}^{-}}$ & $k_{\mathrm{Cl}_{2}^{-}}$ \\
\hline TW80 & $9.9 \pm 0.1 \times 10^{9}$ & $4.6 \pm 0.2 \times 10^{9}$ & $7.1 \pm 0.1 \times 10^{6}$ \\
PHE & $6.1 \pm 0.2 \times 10^{9}$ & $4.3 \pm 0.4 \times 10^{9}$ & $4.6 \pm 0.3 \times 10^{8}$ \\
\hline
\end{tabular}

591

592 
594

595

596

597

598

599

600

601

602

603

604

605

606

607

608

609

610

1) Absorption spectra of $\mathrm{Fe}(\mathrm{III})-\mathrm{EDDS}(0.5 \mathrm{mM}), \mathrm{S}_{2} \mathrm{O}_{8}{ }^{2-}(5 \mathrm{mM})$ and $90 \mu \mathrm{M}$ of PHE in $0.5 \mathrm{~g} \mathrm{~L}^{-1}$ of TW80. Emission spectrum of the adopted irradiation lamps with a maximum centred at $365 \mathrm{~nm}$.

2) Degradation of PHE in TW80 $0.5 \mathrm{gL}^{-1}$ and degradation of Fe(III)-EDDS in different systems ( Blue marked ). Initial conditions are: $[\mathrm{PS}]=5 \mathrm{mM},[\mathrm{Fe}(\mathrm{III})]=0.5 \mathrm{mM}$, $[\mathrm{Fe}(\mathrm{III})-\mathrm{EDDS}]=0.5 \mathrm{mM},[\mathrm{TW} 80]=0.5 \mathrm{~g} \mathrm{~L}^{-1}, \mathrm{pH}: 3.5 \pm 0.2$.

3) A) Influence of $\mathrm{Fe}(\mathrm{III})$-EDDS concentration on the photodegradation of PHE in aqueous solution. B) Degradation percentage of PHE after 30 and 150 minutes of irradiation as a function of different Fe(III)-EDDS concentrations. Initial conditions are: $[\mathrm{PS}]=5 \mathrm{mM},[\mathrm{TW} 80]=0.5 \mathrm{~g} \mathrm{~L}^{-1}$ and $\mathrm{pH}: 3.5 \pm 0.2$.

4) Influence of PS concentration on the photodegradation of PHE in aqueous solution. Initial conditions are: $[\mathrm{Fe}(\mathrm{III})-\mathrm{EDDS}]=5 \mathrm{mM},[\mathrm{TW} 80]=0.5 \mathrm{~g} \mathrm{~L}^{-1}$ and $\mathrm{pH}: 3.5 \pm 0.2$.

5) Influence of concentration of $\mathrm{Cl}^{-}$for photodegradation of PHE in aqueous solution. $[\mathrm{PS}]=5 \mathrm{mM},[\mathrm{Fe}(\mathrm{III})-\mathrm{EDDS}]=5 \mathrm{mM},[\mathrm{TW} 80]=0.5 \mathrm{~g} \mathrm{~L}^{-1}$ and $\mathrm{pH}: 3.5 \pm 0.2$.

6) Free radical scavenging tests photodegradation of PHE in aqueous solution. [PS] = $5 \mathrm{mM},[\mathrm{Fe}(\mathrm{III})-\mathrm{EDDS}]=0.5 \mathrm{mM}$. [tert-Butanol $]=50 \mathrm{mM},[$ Methanol $]=50 \mathrm{mM}, \mathrm{pH}$ : $3.5 \pm 0.2$. 


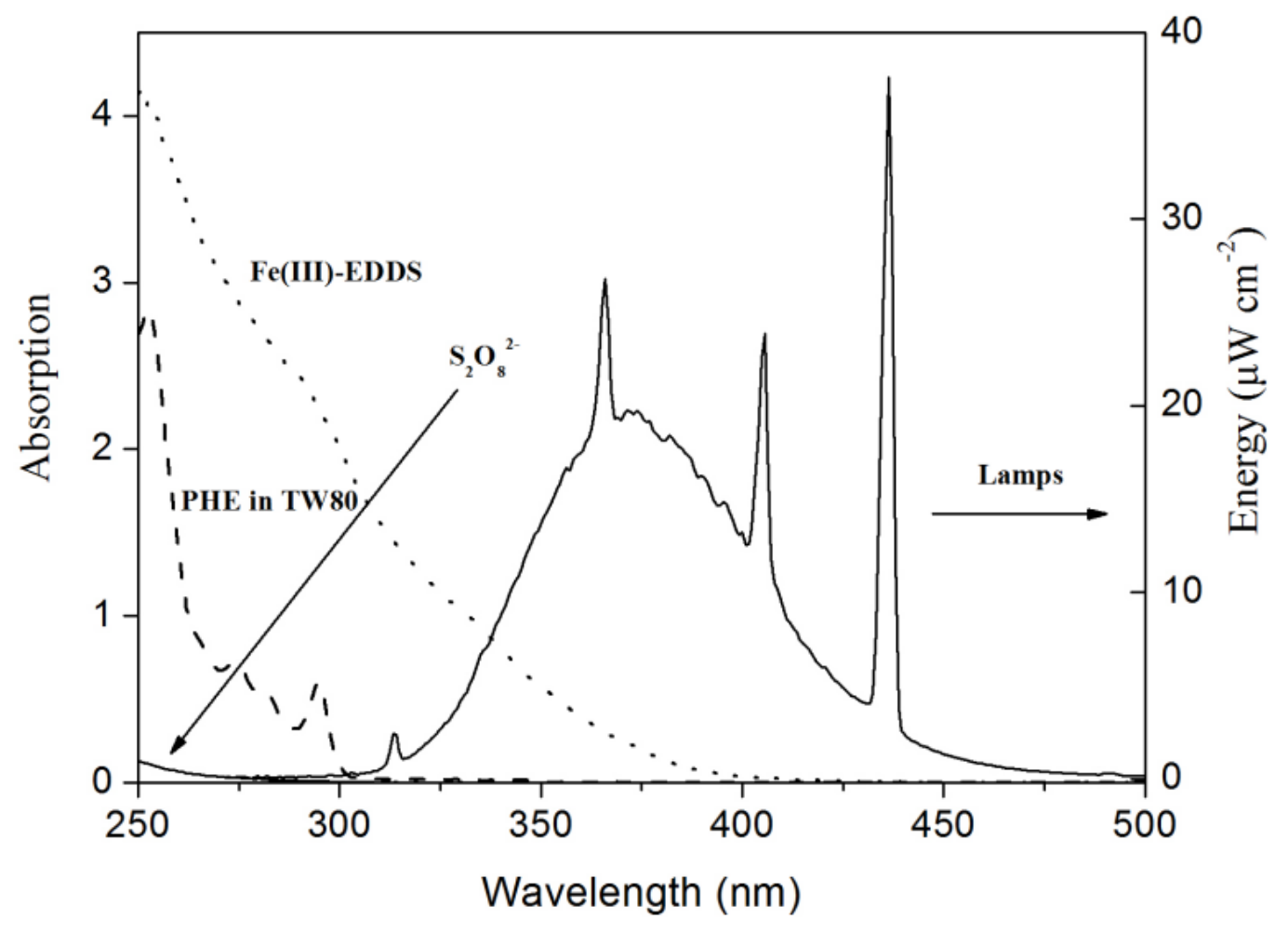

613

614

615

616

617

618

619

620

621

622

623

624

625 


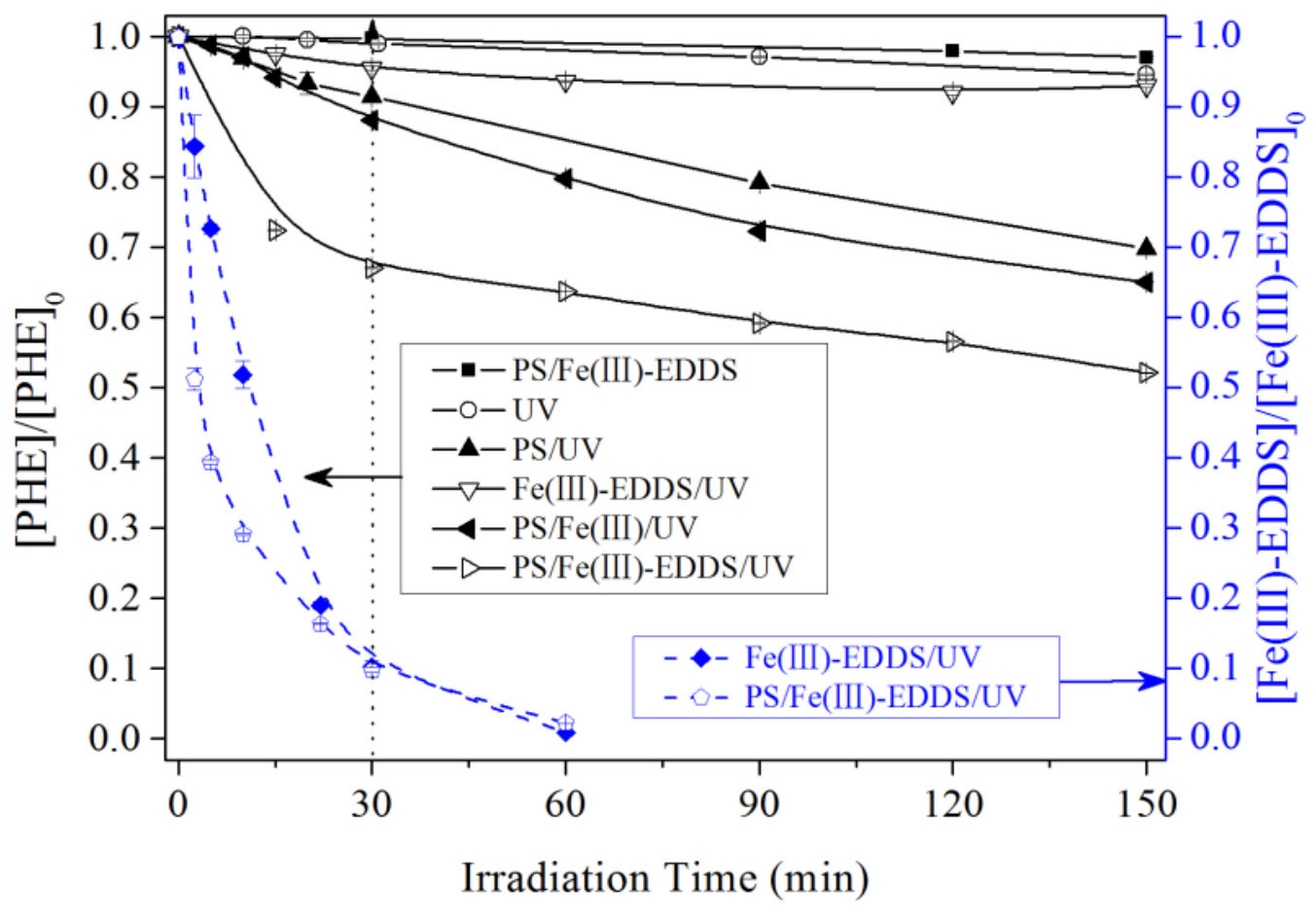



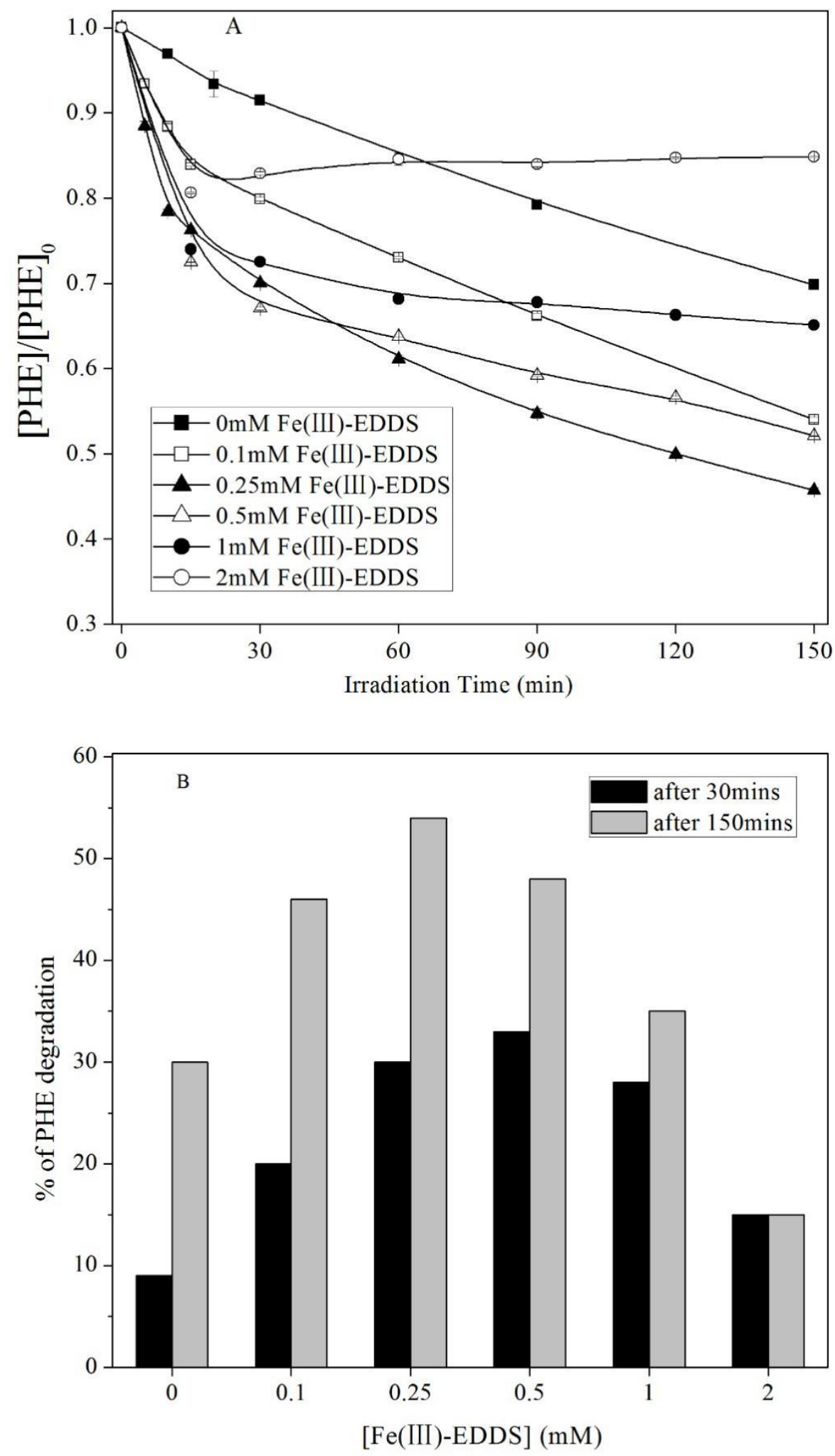


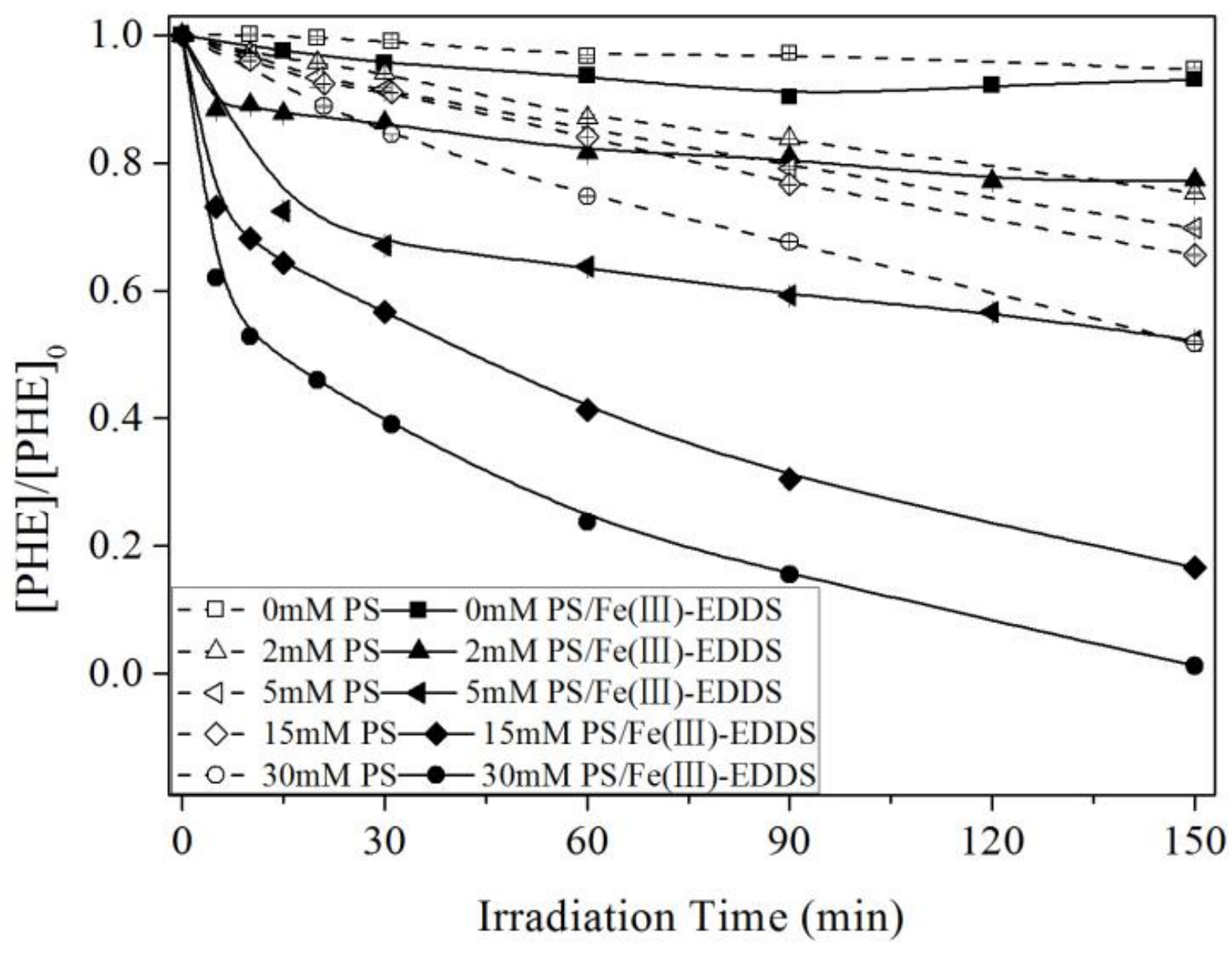




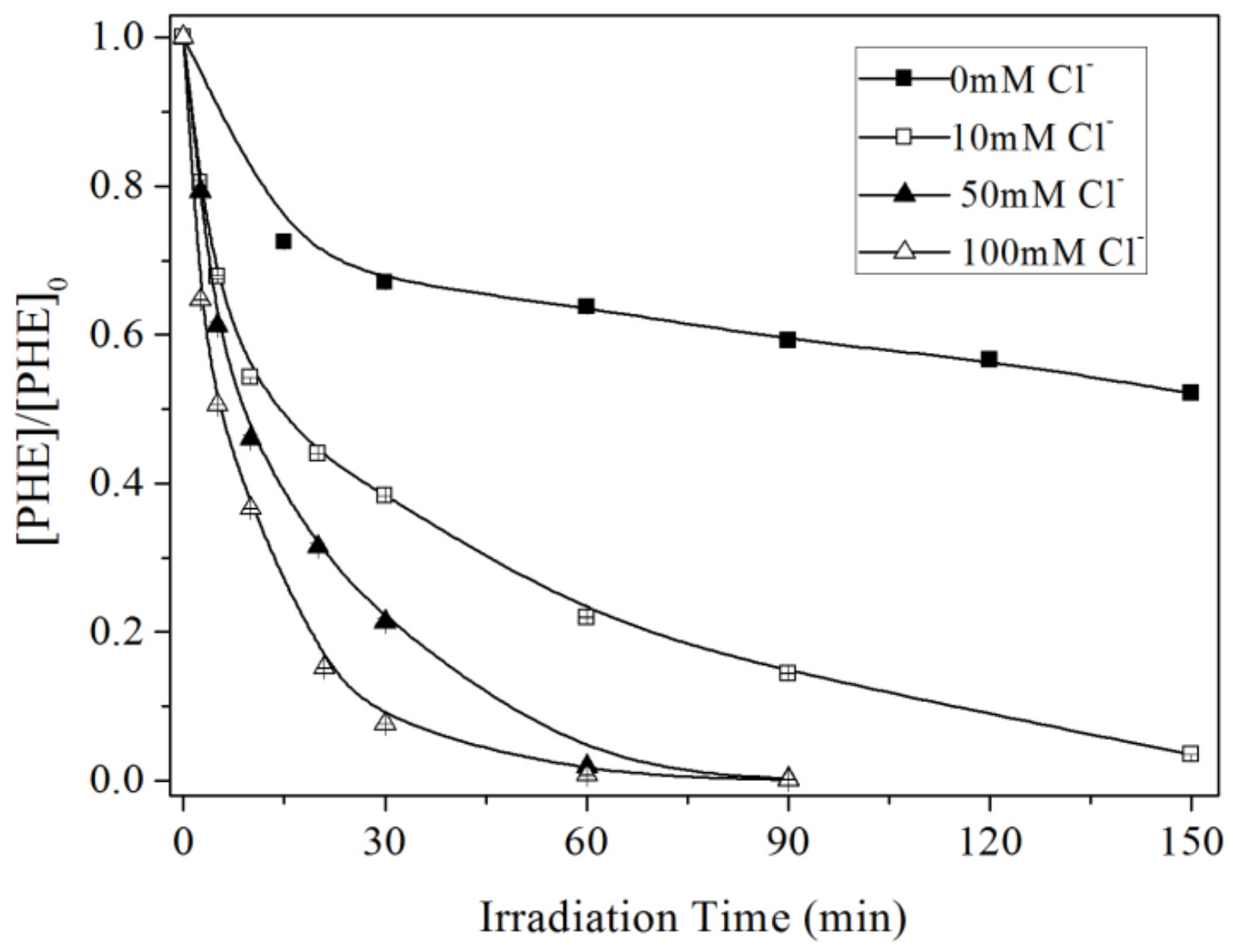




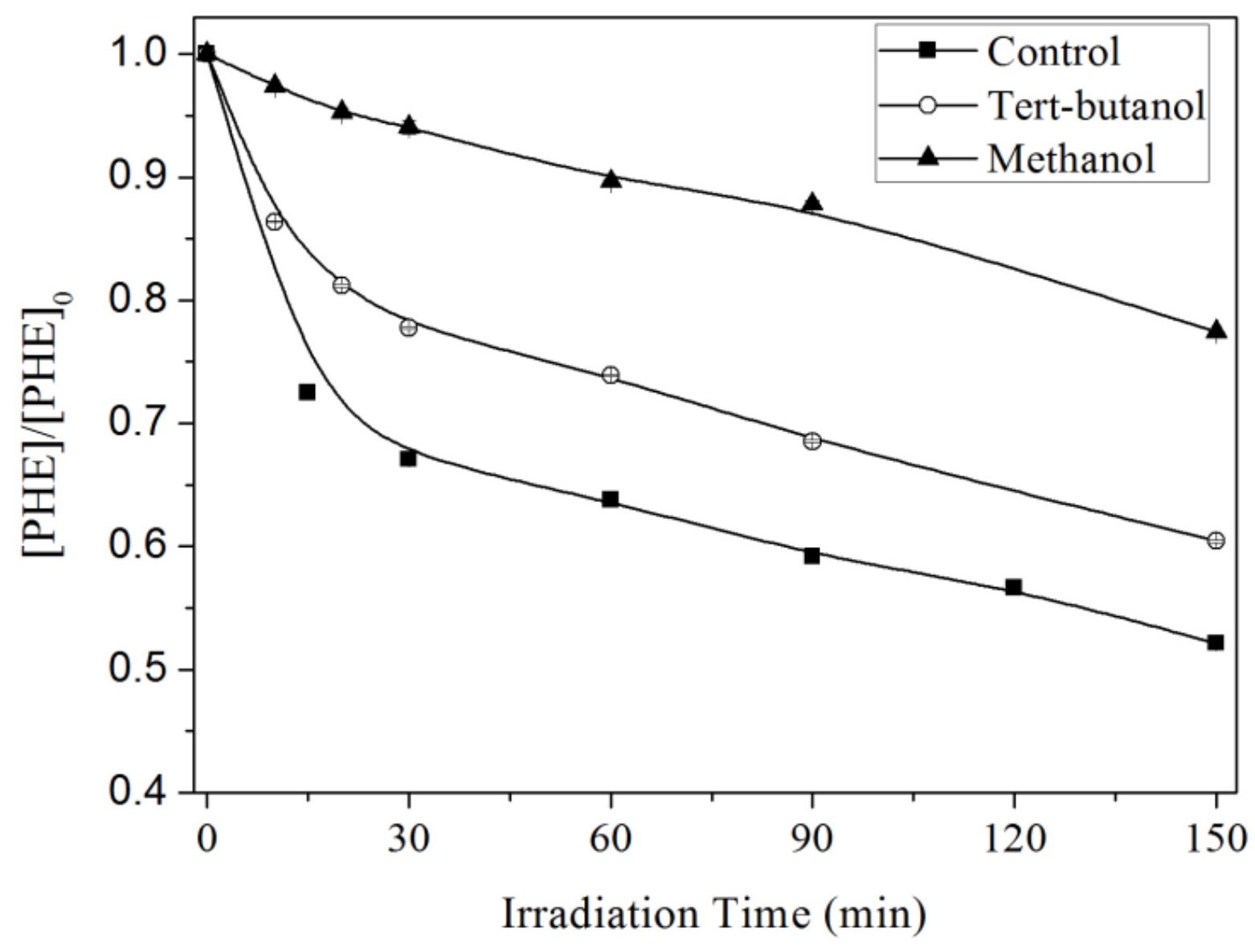

670

671 